\title{
BMJ Open Economic returns to medical research funding
}

\author{
Jonathan Grant, ${ }^{1}$ Martin J Buxton²
}

To cite: Grant J, Buxton MJ. Economic returns to medical research funding. BMJ Open 2018:8:e022131. doi:10.1136/ bmjopen-2018-022131

- Prepublication history for this paper is available online. To view these files, please visit the journal online (http://dx.doi org/10.1136/bmjopen-2018022131).

Received 2 February 2018 Revised 24 May 2018 Accepted 24 July 2018
Check for updates

(C) Author(s) (or their employer(s)) 2018. Re-use permitted under CC BY-NC. No commercial re-use. See rights and permissions. Published by BMJ.

1Policy Institute at King's, King's College London, London, UK ${ }^{2}$ Health Economic Research Group, Brunel University London, Uxbridge, UK

Correspondence to Professor Jonathan Grant; jonathan.grant@kcl.ac.uk

\section{ABSTRACT \\ Following the publication of the final paper in a planned series of four studies estimating the economic returns from biomedical and health research, we reflect on what we have learnt from these types of assessment.}

We recently published a paper estimating the return on investment from musculoskeletal disease (MSD) research funded by the UK government and medical research charities. ${ }^{1}$ This is the final publication in a series of studies that have assessed the economic returns from medical research in the UK. ${ }^{1-4}$ These show that the rates of return measured in terms of the additional health gain that earlier UK research has provided have been in the range of $7 \%-10 \%$ per annum. In addition, our estimates show a further $15 \%$ rate of return in terms of broader economic benefits. Comparisons with other public sector research investments are difficult due to methodological inconsistencies but these figures are well in excess of the yields of $6 \%-8 \%$ that governments typically expect from public investments. ${ }^{5}$

There are a number of reasons to assess the economic returns from research, as have been reviewed elsewhere. ${ }^{67}$ In this communication, we are focusing on the accountability and advocacy to support future investment in research, and on the need for transparent analysis to understand where, how and when returns from research occur.

\section{THE CASE FOR INVESTMENTS IN MEDICAL RESEARCH}

Science funding is under threat. Economic austerity, antiexpert sentiment and increased demands on public expenditure for schools, welfare and defence, and so on, all increase the pressure on science budgets. Last year, the National Institutes of Health escaped significant cuts, but the expectation is that these are still just around the corner. In the UK, Brexit threatens access to over $£ 800$ million of European Union research funding currently going to universities each year. Being able to speak the language of finance ministries is essential in making the case for funding, but estimating the financial returns to the investment in science proves to be devilishly difficult. You need to be able to value benefits in monetary terms; the time between investment and return is typically long; research is an international endeavour making it difficult to attribute returns to national investments; and you need lots and lots of data over long periods of time.

The first of those problems can be overcome in the case of medical research, which includes basic biomedical research through to applied clinical and health services research. The health gains arising from medical research can be measured and monetarised through quality-adjusted life years (QALY). A QALY is a measure of the health of a person or population which incorporates both length of life and the quality of that life, so one QALY is equal to 1 year of life in full health. It is widely used in healthcare prioritisation to assess the value for money of different medical interventions, as it is possible to assign a monetary value to a QALY, although the choice of value to assign raises important conceptual issues and is controversial.

Nevertheless, to date, research to assess the value of the benefits of medical research forms a relatively small and developing field. ${ }^{8}$ Early approaches looked at productivity gains from a healthy workforce, but these tended to overstate the benefits as lost labour can be replaced by unemployed people or through immigration, and ignore health gains for groups such as children and the elderly. Other research has attempted to estimate the health gains themselves and valued the overall increase in longevity using a high value of life based on the willingness of individuals to pay for small reductions in the risk of death. Academic work by a number of US economists was given prominence as the supposed basis for the now discredited claims of 'Funding First', a US lobby group now disbanded. ${ }^{9}$ Their claims of 'Exceptional Returns' went well beyond the underpinning academic papers 
subsequently published. ${ }^{10}$ A broadly similar approach was adopted in a series of Australian studies conducted by Access Economics, ${ }^{11}$ but expanded to allow for improvements in quality of life based on disability-adjusted life years. In the 2003 version of the Australian analysis, no allowance was made for the time between the research investment and the improvements in health. In the 2008 and 2011 iterations, this was addressed by 'crystal ball' projections of the potential health and well-being gains 40 years into the future. However, the main problem with all these top-down approaches is the overall gain in mortality or morbidity is not linked to specific interventions. This means that a critical assumption has to be made regarding what proportion of the total gain in life expectancy is assumed to result from the application of medical research rather than, for example, general improvements in living standards. One way of addressing this problem of attribution is by examining, in a bottom-up manner, the impacts on specific clinical areas by tracing forwards from the research to the benefits that arise.

\section{ESTIMATING THE ECONOMIC RETURNS OF MEDICAL RESEARCH}

This is exactly what we did. We analysed two major elements of economic returns: the monetised health gains from the UK application of relevant UK research, and the broader impact on the UK gross domestic product (GDP).

To assess the health gains, we estimated the amount of public (government and charity) money spent in three different areas- cardiovascular disease (CVD), cancer and MSD research; the elapsed time between investment and return; the amount of health gain that should be attributed to the national research investment; and the net monetary benefits (NMB) arising from the research, defined as the health benefit valued in monetary terms minus the cost of delivering that health benefit, for a list of major clinical interventions (see figure 1). We valued QALYs not in terms of a social willingness to pay but in terms of the opportunity cost based on an estimate of how much it costs the UK National Health Service to generate an extra QALY (with a base case of £25 000). Using these four key elements of data, we could then attribute a proportion of the annual NMB of the health gain as being due to UK research, and relate an equal number of years of investment to years of NMB, 'lagged' by an estimate of the average time between research and benefit. The return is expressed as an internal rate of return (IRR), which is effectively the discount rate that would yield a zero net present value. As summarised in table 1 , for CVD research this produced a best-case estimate of $9 \%,{ }^{2}$ and when this approach was applied to cancer and MSD research the respective IRR was $10 \%^{3}$ and $7 \% .^{1}$

To estimate the overall value of public medical research investments, more general returns to the economy need to be added to these 'health' returns. The term 'spillover' is used by economists to describe an investment by one organisation, public or private, that benefits other organisations in the same sector of the economy and in any other sector of the economy. For example, life sciences companies build on and interact with publicly funded research, conduct further research themselves and bring medicines and technologies into use in healthcare. In other words, public medical research spend can boost private sector research spend (and vice versa).

So, to estimate the economic benefit of medical research investments, it is important to determine the magnitude of impact that public spend has on private sector research and development (R\&D) investment (in economic terms, the elasticity). The resulting elasticity can then be combined with estimates of the social rate of return to private sector R\&D investment to estimate the economic rate of return (GDP gain) obtained from

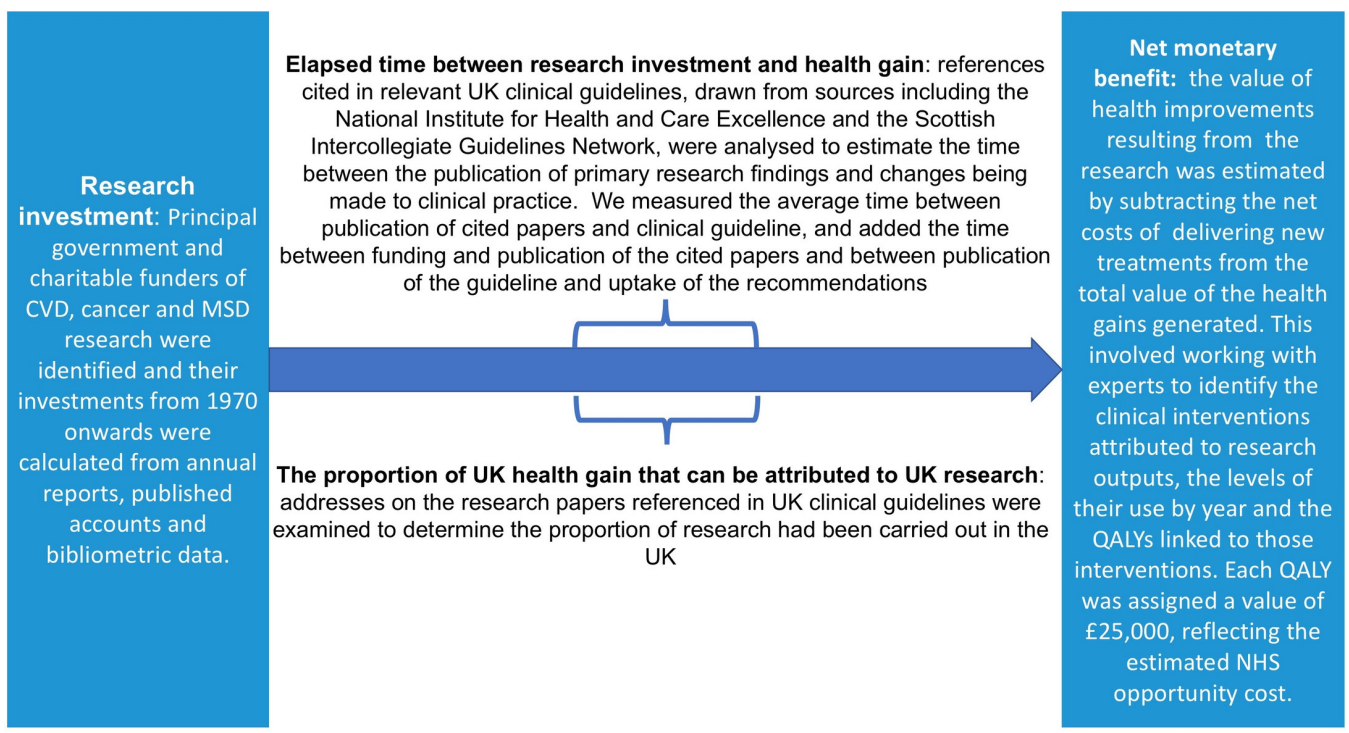

Figure 1 Conceptual approach to assessing the economic returns of medical research funding. CVD, cardiovascular disease; MSD, musculoskeletal disease; NHS, National Health Service; QALY, quality-adjusted life year. 


\begin{tabular}{|c|c|c|c|}
\hline & MSD & Cancer & CVD \\
\hline $\begin{array}{l}\text { Average annual research investment } \\
\text { (for years of data used in IRR calculation as reported in source } \\
\text { publications, using different time period for calculating constant } \\
\text { prices and therefore not suitable for comparisons) }\end{array}$ & $\begin{array}{l}\text { £70 million } \\
(1978-1997, \\
\text { in constant } \\
2013 / 2014 \text { prices })\end{array}$ & $\begin{array}{l}£ 266 \text { million } \\
(1976-1995, \\
\text { in constant } \\
2011 / 2012 \text { prices })\end{array}$ & $\begin{array}{l}£ 111 \text { million } \\
(1975-1998, \\
\text { in constant } \\
2005 / 2006 \text { prices })\end{array}$ \\
\hline $\begin{array}{l}\text { Average annual research investment } \\
\text { (rebased in same constant prices for comparative purposes) }\end{array}$ & $\begin{array}{l}£ 70 \text { million } \\
(1978-1997, \\
\text { in constant } \\
2013 / 2014 \text { prices) }\end{array}$ & $\begin{array}{l}£ 290 \text { million } \\
(1976-1995, \\
\text { in constant } \\
2013 / 2014 \text { prices) }\end{array}$ & $\begin{array}{l}£ 133 \text { million } \\
(1975-1998, \\
\text { in constant } \\
2013 / 2014 \text { prices) }\end{array}$ \\
\hline $\begin{array}{l}\text { Elapsed time } \\
\text { (between spending on research and health gain) }\end{array}$ & 16 years & 15 years & 17 years \\
\hline $\begin{array}{l}\text { Attribution } \\
\text { (proportion of papers that include a UK address from the papers } \\
\text { cited on guidelines) }\end{array}$ & $30 \%$ & $17 \%$ & $17 \%$ \\
\hline $\begin{array}{l}\text { Average NMB } \\
\text { (rebased in same constant prices for comparative purposes) }\end{array}$ & $\begin{array}{l}£ 801 \text { million } \\
(1994-2013, \\
\text { in constant } \\
2013 / 2014 \text { prices })\end{array}$ & $\begin{array}{l}\text { £6458 million } \\
(1991-2010, \\
\text { in constant } \\
2013 / 2014 \text { prices })\end{array}$ & $\begin{array}{l}£ 3559 \text { million } \\
(1992-2005, \\
\text { in constant } \\
2013 / 2014 \text { prices })\end{array}$ \\
\hline IRR (health gain) & $7 \%$ & $10 \%$ & $9 \%$ \\
\hline
\end{tabular}

CVD, cardiovascular disease; IRR, internal rate of return; MSD, musculoskeletal disease.

public medical research investment. Using an econometric model, as described in Sussex $e t a l \mathrm{~s}^{4}$ study, it was possible to demonstrate that every additional $£ 1$ of public spend on medical research is associated with an eventual additional $£ 0.99$ of private R\&D spend in the UK. By combining the estimated elasticity with previous estimates of the social rate of return from private R\&D spend of around $50 \%$, the best estimate IRR, in terms of impact on GDP of public medical research spend, was between $15 \%$ and $18 \% .{ }^{4}$ In other words, a $£ 1$ investment in UK public medical research would benefit the UK economy to an extent equivalent to receiving 15-18 pence per year in interest in return for that investment.

While technically our health return represents an average for the total CVD, cancer and MSD research in the UK, and the spillover estimates are for a marginal change in (any) health-related public research, it is not unreasonable to see them as additive. ${ }^{2}$ Thus, adding to the estimates of the NMB of health gains arising from research, this would suggest a total return to CVD, cancer and MSD research of around 25\% (ie, circa $10 \%$ for the health gains plus circa $15 \%$ for the GDP gain). This means that for every $£ 1$ spent on medical research in the UK, we get back benefits, in GDP gains and health gains, equivalent to 25 pence per year.

\section{WHAT WE LEARNT}

These estimates are imperfect. They rely on incomplete data and surrogate measures, and necessarily involve many detailed assumptions. But they aim to be conservative, they are relatively transparent and they are open to detailed critique. They represent a challenge to other research sectors to similarly attempt to quantify returns. As previously noted in an editorial in Nature in 2010, reporting on the first of these studies, they are 'a genuine attempt objectively to assess the economic outcomes of research.' ${ }^{12}$

They are of course also estimates of what has been the return on past research investments. They reflect past performance and are no guarantee of similar future returns. They also report the average rate of return, not the marginal rate of return from an additional investment which would indicate whether returns to investment are diminishing as some commentators fear. ${ }^{13}$

But analyses of this sort do not just provide numbers that demonstrate that the return to medical research funding is substantial, the studies also highlight core areas of uncertainty and issues that need further exploration to inform policy responses. For example, across the three studies, the average time between research and significant health gain ranges from 15 to 17 years-an estimate that is reinforced by other studies. ${ }^{14}$ This illustrates the intergenerational nature of research funding and emphasises that funding changes cannot be judged in the short term. It also supports efforts to 'accelerate' the research translation pathway.

The other interesting observation is the international nature of research-between $17 \%$ and $30 \%$ of the benefit to the UK population in terms of improved health is derived from UK research. Put another way 
round three-quarters of health gains in the UK arise from research undertaken in other countries. The differences between disease areas in these estimates need further exploration, but as we seemingly enter a period of greater national protectionism, it is more important than ever to recognise the global nature of research and the benefit that brings to both national and international populations. A country could decide to 'free load' on the research of others or to contribute to the collective global effort. The appropriate balance probably depends on a mix of the country's wealth, health, the relevance of the international research effort to its particular health problems and a judgement on the relative spillover effect of this use of public funds.

Overall, it is worth stressing that this type of research is dependent on historical data series of both research investments and the cost-effectiveness of interventions. Both are hard to create. For research funding data, this is in part because archive data are not readily available, and when they are, they do not historically use the same classification systems-both over time and between funders. A key lesson-which has been picked up by funders in the UK-is to use a standard taxonomy of research funding and to apply that over time. ${ }^{15}$ Cost-effectiveness data are easier to find for pharmaceutical interventions than for non-surgical interventions (such as back pain) reflecting the focus of much health technology assessments. Nevertheless, for both types of intervention you then need to build up the annual streams of net health gain for each specific intervention by specific patient groups, for specific conditions and for different severities. And this takes time-about 18-24months to collate and compile the necessary data to make the rate of return estimate.

\section{THE NEED FOR RESEARCH ON RESEARCH}

Previous attempts to measure the returns from research have been motivated by lobbying for science funding. Claimed returns that are not well based in firm evidence are likely, in the end, to be counterproductive for the research community. Research on research needs to be conducted to the same standards of rigour and robustness as all high-quality research, and subject to the same critical review. In the current climate towards science, researchers cannot simply rely on the view that research is, by definition, a 'good thing'. Funders and the research community need to be able to demonstrate the value of what they do: the studies mentioned here are important first steps.

Contributors The paper was conceived by JG and MJB who made an equal contribiton to the paper, critically reviewing various iterations and approving the final draft submitted.
Funding This paper was not supported by direct funding. The studies synthesised in the paper were funded through a series of research grant from the Wellcome Trust, Arthritis Research UK, the Medical Research Council (MRC), National Institutes for Health Research (NIHR), Academy of Medical Sciences and Cancer Research UK.

Competing interests None declared.

Patient consent Not required.

Provenance and peer review Not commissioned; externally peer reviewed.

Data sharing statement The synthesised data used and generated during this study are included in the cited papers and additional files.

Open access This is an open access article distributed in accordance with the Creative Commons Attribution Non Commercial (CC BY-NC 4.0) license, which permits others to distribute, remix, adapt, build upon this work non-commercially, and license their derivative works on different terms, provided the original work is properly cited, appropriate credit is given, any changes made indicated, and the use is non-commercial. See: http:// creativecommons.org/licenses/by-nc/4.0/.

\section{REFERENCES}

1. Glover M, Montague E, Pollitt A, et al. Estimating the returns to United Kingdom publicly funded musculoskeletal disease research in terms of net value of improved health outcomes. Health Res Policy Syst 2018;16:1.

2. Buxton M, Hanney S, Morris S, et al. Medical research: what's it worth?: estimating the economic benefits from medical research in the UK: Wellcome Trust/AMS/MRC, 2008.

3. Glover M, Buxton M, Guthrie S, et al. Estimating the returns to UK publicly funded cancer-related research in terms of the net value of improved health outcomes. BMC Med 2014;12:99.

4. Sussex J, Feng Y, Mestre-Ferrandiz J, et al. Quantifying the economic impact of government and charity funding of medical research on private research and development funding in the United Kingdom. BMC Med 2016;14:32.

5. Zerbe RO. Regulation. Winter 2013-2014.

6. Morgan Jones M, Grant J. Making the grade: methodologies for assessing and evidencing research impact. In: Dean AWM, Stevens $\mathrm{H}$, eds. Seven essays on impact DESCRIBE project report for JISC. Exeter: University of Exeter, 2013:25-43.

7. Deeming $S$, Searles A, Reeves $P$, et al. Measuring research impact in Australia's medical research institutes: a scoping literature review of the objectives for and an assessment of the capabilities of research impact assessment frameworks. Health Res Policy Syst 2017;15:22.

8. Raftery J, Hanney S, Greenhalgh T, et al. Models and applications for measuring the impact of health research: update of a systematic review for the health technology assessment programme. Health Technol Assess 2016;20:1-254.

9. First F. Exceptional Returns: The economic value of America's investment in medical research: Lasker Foundation, 2000.

10. Murphy KM, Topel RH. Measuring the gains from medical research. An economic approach Univesity of Chigarco Press 2003.

11. Access Economics. Exceptional Returns: The Value of Investing in Health R\&D in Australia. (Access Economics, 2003). Access Economics. Exceptional Returns: The Value of Investing in Health R\&D in Australia II. (Access Economics, 2008). Deloitte Access Economics: Returns on NHMRC funded Research and Development. (Deloitte Access Economics, 2011).

12. Editorial: Unknown quantities. Nature 2010;465:665-6.

13. Bowen A, Casadevall A. Increasing disparities between resource inputs and outcomes, as measured by certain health deliverables, in biomedical research. Proc Natl Acad Sci U S A 2015;112:11335-40.

14. Morris ZS, Wooding S, Grant J, et al. The answer is 17 years, what is the question: understanding time lags in translational research. J R Soc Med 2011;104:510-20.

15. UKCRC Health Research Classification System. Origins and future of the HRCS. https://www.hrcsonline.net (accessed 23 May 2018). 